\title{
A narrative review of new treatment options for chronic kidney disease in type 2 diabetes
}

\author{
Frederik Persson $^{1}$, Rikke Borg ${ }^{2,3}$, Peter Rossing ${ }^{1,3}$ \\ ${ }^{1}$ Steno Diabetes Center Copenhagen, Denmark; ${ }^{2}$ Zealand University Hospital Roskilde, Denmark; ${ }^{3}$ Institute for Clinical Medicine, University of \\ Copenhagen, Denmark \\ Contributions: (I) Conception and design: F Persson, R Borg; (II) Administrative support: None; (III) Provision of study materials or patients: none; \\ (IV) Collection and assembly of data: F Persson, R Borg; (V) Data analysis and interpretation: All authors; (VI) Manuscript writing: All authors; (VII) \\ Final approval of manuscript: All authors. \\ Correspondence to: Frederik Persson. Steno Diabetes Center Copenhagen, Niels Steensensvej 1, 2820 Gentofte, Denmark. \\ Email: frederik.persson@regionh.dk.
}

\begin{abstract}
Diabetic kidney disease is a frequent and costly complication to type 2 diabetes. After many years with a lack of successful trials there are now significant developments that will change treatment, guidelines and future outcome. Since the last two decades blockade of the renin-angiotensin system (RAS) is standard treatment, but new antidiabetic treatments have shown potential for kidney protection. After cardiovascular outcome studies with glucagon-like peptide (GLP-1) receptor agonists it is evident that drugs like liraglutide, semaglutide and dulaglutide can reduce albuminuria levels and progression to macroalbuminuria. At present, a renal outcome trial with semaglutide is ongoing which will provide more evidence on the drug class in the future. The sodium glucose co-transporter 2 (SGLT2) inhibitor class has also demonstrated effects beyond glucose-lowering, as the drugs can reduce blood pressure, albuminuria and loss of renal function. In the first renal outcome study the SGLT2 inhibitor canagliflozin was found to reduce the risk of hard renal outcome with $30 \%$. SGLT2 inhibition is now recommended in type 2 diabetes with chronic kidney disease. Renal outcome studies testing additional SGLT2 inhibitors and the GLP-1 receptor agonist semaglutide will report in the coming future potentially providing more and much needed options for treatment.
\end{abstract}

Keywords: Albuminuria; diabetic kidney disease; glomerular filtration rate; dialysis; type 2 diabetes

Submitted Jun 20, 2020. Accepted for publication Dec 18, 2020.

doi: 10.21037/atm-20-4841

View this article at: http://dx.doi.org/10.21037/atm-20-4841

\section{Introduction}

Much of the increased morbidity and mortality in type 2 diabetes (T2D) occurs in individuals who develop diabetic kidney disease. Mortality is mainly seen in people with microalbuminuria [urinary albumin creatinine ratio (UACR): $30-300 \mathrm{mg} / \mathrm{g}$ ] or macroalbuminuria ( $>300 \mathrm{mg} / \mathrm{g}$ ) and is not only due to renal failure but to a high degree of cardiovascular disease (1). The individual risk of developing chronic renal failure has decreased during recent decades due to improved T2D treatment with increased focus on lifestyle factors, and pharmacological glucose lowering, blood pressure control and lipid lowering therapy. However, the proportion of individuals with diabetic kidney disease as a cause of chronic kidney failure is more or less constant due to the increased prevalence of T2D and improvement in overall survival. Diabetic kidney disease accounts for approx. $25 \%$ of people in dialysis treatment in Denmark and approx. $40 \%$ in the US. This group of individuals have a particularly high cardiovascular morbidity and mortality. Thus, early detection with systematic measurement of albuminuria, as well as multifactorial prevention, remains important. Over the last few years, new treatment options have emerged. We present the following article in accordance with the Narrative Review reporting checklist (available at http://dx.doi.org/10.21037/atm-20-4841). 
Table 1 Screening for diabetic kidney disease. Day-to-day variation in albuminuria can be up to $30 \%$, so repeated urine testing is necessary

\begin{tabular}{|c|c|c|c|}
\hline Category & \multicolumn{3}{|c|}{ Definitions based on urinary levels of albumin } \\
\hline Normal $^{1}$ & $<30$ & $<30$ & $<20$ \\
\hline Microalbuminuria $^{2}$ & $30-300$ & $30-299$ & $20-199$ \\
\hline Macroalbuminuria $^{3}$ & $>300$ & $>300$ & $>200$ \\
\hline
\end{tabular}

${ }^{*}$, first morning void recommended due to low day-to-day variability; ${ }^{1}$, also termed normal to mildly increased (KDIGO); ${ }^{2}$, also termed moderately increased (KDIGO); ${ }^{3}$, also termed severely increased (KDIGO).

\section{Diagnosis and clinical epidemiology}

In clinical practice, the diagnosis of diabetic nephropathy is defined as:

* Persistent macroalbuminuria: Urinary albumin/ creatinine ratio $\geq 300 \mathrm{mg} / \mathrm{g}$ in at least two out of three urine samples measured in a 1-12-month interval

* Exclusion of non-diabetic kidney disease

Other conditions support the diagnosis:

* Hypertension (seen in $>90 \%$ )

* Diabetic retinopathy (seen in $>60 \%$; reflecting the presence of microvascular disease)

The precise diagnosis is established by kidney biopsy. However, in most cases, this invasive procedure is abstained from if disease course and clinical presentation concur (1). A broader and less specific term is diabetic kidney disease or chronic kidney disease (CKD) in diabetes which is defined by proteinuria and or reduced GFR in a person with diabetes but does not imply anything on the pathogenesis.

Global incidence of micro- and macroalbuminuria in T2D is approx. $50 \%$ (2). In 2017, 10.6\% of the Danish T2D population had macroalbuminuria. In individuals with recently diagnosed $\mathrm{T} 2 \mathrm{D}$, about $3 \%$ already have signs of nephropathy. The risk of developing diabetic nephropathy in a normoalbuminuric person with a diabetes duration $>30$ years is low. Risk factors for progression to chronic kidney disease in type 2 diabetes include hypertension, smoking, male gender and elevated $\mathrm{HbA}_{1 c}$.

\section{Pathology}

The predominant cause of chronic diabetic complications is long-term exposure to hyperglycemia. The vascular endothelial cells are not able to down-regulate cell membrane glucose transport, leading to elevated intracellular glucose concentrations, causing oxidative stress and shifts in cellular glucose metabolism (3). Damage forms in the endothelial cells of the kidney's glomerular capillaries. In addition, the podocytes, which are important for the permeability of the glomerular basement membrane, are damaged resulting in the passage of albumin from blood to urine.

Over time, distinct changes in the kidney structure occur. The classic glomerulosclerosis is characterized by increased width of the glomerular basement membrane, mesangial sclerosis, microaneurysms and hyaline arteriosclerosis. In addition, interstitial inflammation and fibrosis develops.

As not everyone with diabetes develops kidney disease, factors other than hyperglycemia are involved. Genetics, ethnicity and diabetes duration have an important impact, as do smoking, cholesterol and hypertension.

\section{Microalbuminuria}

Annual screening for microalbuminuria aims to identify individuals at increased risk of developing diabetic nephropathy who are at need for renoprotective therapy (4) (Table 1). It is recommended to measure urine-albumincreatinine (UACR) ratio in spot urine samples for both screening and monitoring. Microalbuminuria is defined as UACR 30-300 $\mathrm{mg}$ albumin per $\mathrm{g}$ creatinine in at least 2 out of 3 urine samples. Day-to-day variation in albuminuria can be up to $30 \%$, so repeated urine testing is necessary. Recent data from a large database including 2.6 million people with CKD from California in the US demonstrated that less than $5 \%$ of subjects with CKD were screened for albuminuria/ proteinuria, and only $20.5 \%$ of subjects with CKD were treated with standard renoprotective therapy (RAS blocking treatment). More patients were treated with potentially kidney toxic agents like NSAIDs (5).

\section{Diabetic nephropathy}

Untreated, the course of diabetic nephropathy will involve a sustained, almost linear decrease in renal function (GFR) of 
approximately $12 \mathrm{~mL} / \mathrm{min} / 1.73 \mathrm{~m}^{2}$ per year with significant inter-individual variation $(2-20 \mathrm{~mL} / \mathrm{min} /$ year $)$.

A number of factors play a role in the progression of diabetic kidney disease. There is a close correlation between blood pressure and the rate of decline in GFR. As the disease progresses, impaired or abrogated renal autoregulation of glomerulus (GFR) filtration and renal plasma flow is seen, exacerbating the deleterious effects of systemic hypertension in the capillaries. Here, the reninangiotensin-aldosterone (RAAS) system plays an important role. It is particularly related to the deleterious effect of angiotensin II, which can lead to inflammation and fibrosis. In addition to regulating electrolyte and fluid balance, aldosterone also has a variety of effects both in the kidney and in other tissues including the vascular system, the central nervous system and the heart. Here, too, fibrosis is the suspected harmful effect (6).

\section{Prevention and treatment}

\section{Glycemic control}

Good glycemic control has a beneficial effect on progression from normoalbuminuria to micro- and macroalbuminuria. This was initially shown in a small Japanese study (7) and the finding was confirmed in the UKPDS (8). The ADVANCE study (9), in which 11,140 patients were followed for a median 5 years, showed that patients randomized to tight glycemic control $\left(\mathrm{HbA}_{1 \mathrm{c}}\right.$ $<48 \mathrm{mmol} / \mathrm{mol}$ or $6.5 \%)$ had a $21 \%(95 \%$ CI: $7-34)$ lower rate of nephropathy compared to patients randomized to standard glycemic control and even end stage kidney disease (ESKD) was reduced in the ADVANCE study (10).

\section{Blood pressure}

The blood pressure in the glomerular capillaries is an important factor in the pathogenesis of diabetic kidney disease. By treating with antihypertensive agents, the glomerular pressure is reduced. After six years of follow-up in the UKPDS study, there were $29 \%$ fewer individuals in the tight blood pressure control group who had developed microalbuminuria (11). A meta-analysis indicates that early intervention with RAAS blockade (in the case of normoalbuminuria), delays the development of microalbuminuria (12). Also, antihypertensive treatment has a renoprotective effect in hypertensive patients with microalbuminuria. The IRMA 2 study (13) investigated 590 hypertensive patients with T2D and microalbuminuria who were randomized to irbesartan either 150 or $300 \mathrm{mg}$ daily or placebo for 2 years. The primary endpoint was the time of onset of diabetic nephropathy. The study showed that irbesartan is renoprotective, independent of the blood pressure lowering effect and that $300 \mathrm{mg}$ daily had the best effect. Similarly, other studies have documented that the renoprotective effect is dose dependent; therefore focus in treatment should be aimed at reaching the maximum tolerated dose.

The basis for RAAS blockade being the standard for treatment of macroalbuminuria are two randomized, placebo-controlled studies with angiotensin II receptor antagonists (ARBs) in populations with hypertension and T2D with macroalbuminuria. The primary endpoint was a combination of a doubling of baseline creatinine concentration, end stage kidney disease (ESKD) or death, which was reduced by $16 \%$ and $20 \%$ in the two studies, respectively $(14,15)$.

Combining ACE inhibitors with $\mathrm{ARB}$ or renin inhibitors is not recommended as such a 'double blockade' increases the incidence of hyperkalaemia, hypotension and acute renal failure without improved efficacy (16-18).

\section{Lipid-lowering treatment}

Observational studies suggest an association between cholesterol concentration and the development of nephropathy. A randomized study has shown that treatment with atorvastatin for one year in people with micro- and macroalbuminuria reduced albuminuria by $18 \%$ with no effect on eGFR (19). The SHARP study, which randomized both dialysis and predialysis patients to simvastatin in combination with ezetimibe versus placebo, demonstrated a beneficial effect on arteriosclerotic endpoints in individuals who started treatment prior to chronic dialysis (20).

The Steno 2 study showed that multifactorial intervention (pharmacological treatment of hyperglycemia, hypertension, dyslipidemia and microalbuminuria, as well as lifestyle intervention) significantly prevents progression to nephropathy, retinopathy and autonomic neuropathy, and reduces cardiovascular disease and mortality (21). Thirteen years after the end of the study, the development of ESKD was reduced to approx. one third in the group with intensive intervention (22).

\section{New treatment options}

Several new anti-diabetic, glucose-lowering drugs have 
shown renoprotective potential. The effect is primarily demonstrated as reduction of albuminuria, while three studies so far has investigated the hard renal outcome as the primary endpoint. The interesting thing is that the effect seems to be related to mechanisms independent of the glucose-lowering effect.

In cardiovascular endpoint studies, some GLP-1 receptor agonists (liraglutide, semaglutide, dulaglutide) (23-28) have shown renoprotective effects in people with T2D. In addition to reducing albuminuria, the treatment may delay the development of macroalbuminuria (29). In some studies, as a secondary endpoint, there have also been minor effects on loss of renal function. No studies have yet been conducted with the development of renal disease as the primary endpoint, but for semaglutide such a study is ongoing. The mechanism GLP-1 RA mediated renoprotection is unknown so far.

SGLT2 inhibitors are another treatment which, in addition to its glucose-lowering effect, have been shown to have a positive effect on cardiovascular death and renal and cardiac failure. Since 2015, when cardiovascular death was reduced in the first study with empagliflozin (30), reduction of albuminuria and decrease in renal function decline have been observed in post-hoc analyses, even at eGFR down to $30 \mathrm{~mL} / \mathrm{min} / 1.73 \mathrm{~m}^{2}$. This is despite the fact that with reduced renal function (eGFR $<60 \mathrm{~mL} / \mathrm{min} / 1.73 \mathrm{~m}^{2}$ ) there is less glucosuria and thus less reduction in $\mathrm{HbA}_{1 \mathrm{c}}$ (31-33). The mechanism is probably a hemodynamic/vascular effect, in which reduced co-reabsorption of sodium with glucose in the tubules leads to decreased glomerular pressure. There were high expectations for the first randomized trial (CREDENCE) in a risk population with macroalbuminuria ( $>300 \mathrm{mg} / \mathrm{g}$ creatinine) and eGFR between $30-90 \mathrm{~mL} / \mathrm{min} / 1.73 \mathrm{~m}^{2}$, where canagliflozin $100 \mathrm{mg}$ daily was compared with standard treatment with a primary renal endpoint. Canagliflozin reduced the incidence of ESKD, doubling of creatinine and cardiovascular and kidney-related mortality by $30 \%$ (34), with an NNT of 22 over 2.6 years. The side effects for participants with renal impairment were similar to those of normal renal function; increased genital infections and rare but increased incidence of ketoacidosis (2.2 vs. 0.2 per 1,000 patient-years).

Against this background, SGLT2 inhibitors are recommended as renal protection therapy in kidney disease in T2D (especially macroalbuminuria and eGFR $30-90 \mathrm{~mL} / \mathrm{min} / 1.73 \mathrm{~m}^{2}$ ) (35). Recently, the DAPA-CKD trial (36), investigating the effect of dapagliflozin on renal outcomes, was stopped prematurely based on input from the data monitoring committee, due to overwhelming efficacy in analyses for the data safety management committee. The publication showed a remarkable $39 \%$ reduction in the primary outcome, a composite of a sustained decline in the estimated GFR of at least 50\%, end-stage kidney disease, or death from renal or cardiovascular causes (37). The number needed to treat to prevent one primary outcome event was 19 and the effect was also present in patients with non-diabetic kidney disease, as about a third of the included patients did not have diabetes at baseline. A study investigating the effect of empagliflozin on renal parameters is ongoing (38).

Small studies using low doses of the aldosterone antagonist spironolactone in addition to ACE or ARB have been shown to reduce albuminuria, but hyperkalemia has been a limiting factor and more importantly endpoint studies are lacking. Finerenone is a new non-steroidal mineralocorticoid receptor antagonist, which in clinical phase 2 studies has shown the potential to reduce albuminuria without increased risk of hyperkalaemia. A specific kidney outcome study in type 2 diabetes (39) showed a $18 \%$ risk reduction for the composite of kidney failure, a sustained decrease of at least $40 \%$ in the eGFR from baseline, or death from renal causes (40).

Treatment with atrasentan, an endothelin receptor antagonist, also showed effect on renal endpoints; with a $35 \%$ lower incidence of the combined endpoint compared to placebo (41). The manufacturer has decided not to market atrasentan, but similar substances are under development.

\section{Conclusions}

Diabetic kidney disease is a frequent and serious complication of type 2 diabetes as it is closely associated with increased morbidity and mortality. Early detection by detection of microalbuminuria and control of risk factors may prevent or slow down development. As evident from recent outcome trials, canagliflozin, dapagliflozin and finerenone have shown results with renal endpoints, leading to more treatments to choose from. Thus, continued focus on the implementation of the established treatment with RAAS blockade and the recently documented treatment with SGLT2 inhibitors remains essential, as outlined in the recent KDIGO guidelines for diabetes management in CKD (42). As the renal outcome trial with semaglutide is awaited, future research will also focus on improved understanding of underlying mechanisms of the new drugs, improved precision in diagnosis and improved 
individualized treatment.

\section{Acknowledgments}

Funding: None.

\section{Footnote}

Reporting Checklist: The authors have completed the Narrative Review reporting checklist. Available at http:// dx.doi.org/10.21037/atm-20-4841

Conflicts of Interest: All authors have completed the ICMJE uniform disclosure form (available at http://dx.doi. org/10.21037/ atm-20-4841). Dr. Persson reports grants, personal fees and non-financial support from Astra Zeneca, grants, personal fees and non-financial support from Novo Nordisk, grants and personal fees from Amgen, personal fees from MSD, personal fees from Eli Lilly, personal fees from Sanofi, personal fees from Novartis, grants, personal fees and non-financial support from Boehringer Ingelheim, outside the submitted work. Dr. Borg reports personal fees from Astra Zeneca, personal fees from Boehringer Ingelheim, personal fees from Mundipharma, outside the submitted work. Dr. Rossing reports grants and other from Astra Zeneca, other from Bayer, other from Boehringer Ingelheim, other from AbbVie, other from Astellas, other from Eli Lilly, grants and other from Novo Nordisk, other from Janssen, outside the submitted work.

Ethical statement: The authors are accountable for all aspects of the work in ensuring that questions related to the accuracy or integrity of any part of the work are appropriately investigated and resolved.

Open Access Statement: This is an Open Access article distributed in accordance with the Creative Commons Attribution-NonCommercial-NoDerivs 4.0 International License (CC BY-NC-ND 4.0), which permits the noncommercial replication and distribution of the article with the strict proviso that no changes or edits are made and the original work is properly cited (including links to both the formal publication through the relevant DOI and the license). See: https://creativecommons.org/licenses/by-nc-nd/4.0/.

\section{References}

1. Persson F, Rossing P. Diagnosis of diabetic kidney disease: state of the art and future perspective. Kidney Int Suppl (2011) 2018;8:2-7.

2. Parving H-H, Lewis JB, Ravid M, et al. Prevalence and risk factors for microalbuminuria in a referred cohort of type II diabetic patients: A global perspective. Kidney Int 2006;69:2057-63.

3. Thomas MC, Brownlee M, Susztak K, et al. Diabetic kidney disease. Nat Rev Dis Primers 2015;1:15018.

4. Parving HH, Persson F, Rossing P. Microalbuminuria: a parameter that has changed diabetes care. Diabetes Res Clin Pract 2015;107:1-8.

5. Tuttle KR, Alicic RZ, Duru OK, et al. Clinical Characteristics of and Risk Factors for Chronic Kidney Disease Among Adults and Children: An Analysis of the CURE-CKD Registry. JAMA Netw Open 2019;2:e1918169.

6. Frimodt-Moller M, Persson F, Rossing P. Mitigating risk of aldosterone in diabetic kidney disease. Curr Opin Nephrol Hypertens 2020;29:145-51.

7. Ohkubo $\mathrm{Y}$, Kishikawa $\mathrm{H}$, Araki E, et al. Intensive insulin therapy prevents the progression of diabetic microvascular complications in Japanese patients with non-insulindependent diabetes mellitus: a randomized prospective 6-year study. Diabetes Res Clin Pract 1995;28:103-17.

8. Holman RR, Paul SK, Bethel MA, et al. 10-year followup of intensive glucose control in type 2 diabetes. $\mathrm{N}$ Engl J Med 2008;359:1577-89.

9. ADVANCE Collaborative Group; Patel A, MacMahon $\mathrm{S}$, et al. Intensive blood glucose control and vascular outcomes in patients with type 2 diabetes. $\mathrm{N}$ Engl J Med 2008;358:2560-72.

10. Perkovic V, Heerspink HL, Chalmers J, et al. Intensive glucose control improves kidney outcomes in patients with type 2 diabetes. Kidney Int 2013;83:517-23.

11. Efficacy of atenolol and captopril in reducing risk of macrovascular and microvascular complications in type 2 diabetes: UKPDS 39. UK Prospective Diabetes Study Group. BMJ 1998;317:713-20.

12. Persson F, Lindhardt M, Rossing P, et al. Prevention of microalbuminuria using early intervention with reninangiotensin system inhibitors in patients with type 2 diabetes: A systematic review. J Renin Angiotensin Aldosterone Syst 2016;17:1470320316652047.

13. Parving HH, Lehnert H, Brochner-Mortensen J, et al. The effect of irbesartan on the development of diabetic nephropathy in patients with type 2 diabetes. $\mathrm{N}$ Engl J Med 2001;345:870-8.

14. Brenner BM, Cooper ME, de Zeeuw D, et al. Effects of 
losartan on renal and cardiovascular outcomes in patients with type 2 diabetes and nephropathy. $\mathrm{N}$ Engl J Med 2001;345:861-9.

15. Lewis EJ, Hunsicker LG, Clarke WR, et al. Renoprotective effect of the angiotensin-receptor antagonist irbesartan in patients with nephropathy due to type 2 diabetes. $\mathrm{N}$ Engl J Med 2001;345:851-60.

16. Fried LF, Emanuele N, Zhang JH, et al. Combined Angiotensin inhibition for the treatment of diabetic nephropathy. N Engl J Med 2013;369:1892-903.

17. Parving HH, Brenner BM, McMurray JJ, et al. Cardiorenal end points in a trial of aliskiren for type 2 diabetes. $\mathrm{N}$ Engl J Med 2012;367:2204-13.

18. Persson F, Rossing P. Sequential RAAS blockade: is it worth the risk? Adv Chronic Kidney Dis 2014;21:159-65.

19. de Zeeuw D, Anzalone DA, Cain VA, et al. Renal effects of atorvastatin and rosuvastatin in patients with diabetes who have progressive renal disease (PLANET I): a randomised clinical trial. Lancet Diabetes Endocrinol 2015;3:181-90.

20. Baigent C, Landray MJ, Reith C, et al. The effects of lowering LDL cholesterol with simvastatin plus ezetimibe in patients with chronic kidney disease (Study of Heart and Renal Protection): a randomised placebo-controlled trial. Lancet 2011;377:2181-92.

21. Gaede P, Oellgaard J, Carstensen B, et al. Years of life gained by multifactorial intervention in patients with type 2 diabetes mellitus and microalbuminuria: 21 years follow-up on the Steno-2 randomised trial. Diabetologia 2016;59:2298-307.

22. Oellgaard J, Gaede P, Rossing P, et al. Intensified multifactorial intervention in type 2 diabetics with microalbuminuria leads to long-term renal benefits. Kidney Int 2017;91:982-8.

23. Marso SP, Daniels GH, Brown-Frandsen K, et al. Liraglutide and Cardiovascular Outcomes in Type 2 Diabetes. N Engl J Med 2016;375:311-22.

24. Marso SP, Bain SC, Consoli A, et al. Semaglutide and Cardiovascular Outcomes in Patients with Type 2 Diabetes. N Engl J Med 2016;375:1834-44.

25. Mann JFE, Orsted DD, Buse JB. Liraglutide and Renal Outcomes in Type 2 Diabetes. N Engl J Med 2017;377:2197-8.

26. Husain M, Birkenfeld AL, Donsmark M, et al. Oral Semaglutide and Cardiovascular Outcomes in Patients with Type 2 Diabetes. N Engl J Med 2019;381:841-51.

27. Gerstein HC, Colhoun HM, Dagenais GR, et al. Dulaglutide and cardiovascular outcomes in type 2 diabetes (REWIND): a double-blind, randomised placebo- controlled trial. Lancet 2019;394:121-30.

28. Gerstein HC, Colhoun HM, Dagenais GR, et al. Dulaglutide and renal outcomes in type 2 diabetes: an exploratory analysis of the REWIND randomised, placebo-controlled trial. Lancet 2019;394:131-8.

29. Kristensen SL, Rorth R, Jhund PS, et al. Cardiovascular, mortality, and kidney outcomes with GLP-1 receptor agonists in patients with type 2 diabetes: a systematic review and meta-analysis of cardiovascular outcome trials. Lancet Diabetes Endocrinol 2019;7:776-85.

30. Zinman B, Wanner C, Lachin JM, et al. Empagliflozin, Cardiovascular Outcomes, and Mortality in Type 2 Diabetes. N Engl J Med 2015;373:2117-28.

31. Cherney DZI, Zinman B, Inzucchi SE, et al. Effects of empagliflozin on the urinary albumin-to-creatinine ratio in patients with type 2 diabetes and established cardiovascular disease: an exploratory analysis from the EMPA-REG OUTCOME randomised, placebo-controlled trial. Lancet Diabetes Endocrinol 2017;5:610-21.

32. Petrykiv S, Sjostrom CD, Greasley PJ, et al. Differential Effects of Dapagliflozin on Cardiovascular Risk Factors at Varying Degrees of Renal Function. Clin J Am Soc Nephrol 2017;12:751-9.

33. Neal B, Perkovic V, Mahaffey KW, et al. Canagliflozin and Cardiovascular and Renal Events in Type 2 Diabetes. N Engl J Med 2017;377:644-57.

34. Perkovic V, Jardine MJ, Neal B, et al. Canagliflozin and Renal Outcomes in Type 2 Diabetes and Nephropathy. $\mathrm{N}$ Engl J Med 2019;380:2295-306.

35. Buse JB, Wexler DJ, Tsapas A, et al. 2019 Update to: Management of Hyperglycemia in Type 2 Diabetes, 2018. A Consensus Report by the American Diabetes Association (ADA) and the European Association for the Study of Diabetes (EASD). Diabetes Care 2020;43:487-93.

36. Heerspink HJL, Stefansson BV, Chertow GM, et al. Rationale and protocol of the Dapagliflozin And Prevention of Adverse outcomes in Chronic Kidney Disease (DAPA-CKD) randomized controlled trial. Nephrol Dial Transplant 2020;35:274-82.

37. Heerspink HJL, Stefánsson BV, Correa-Rotter R, et al. Dapagliflozin in Patients with Chronic Kidney Disease. N Engl J Med 2020;383:1436-46.

38. Herrington WG, Preiss D, Haynes R, et al. The potential for improving cardio-renal outcomes by sodium-glucose co-transporter-2 inhibition in people with chronic kidney disease: a rationale for the EMPA-KIDNEY study. Clin Kidney J 2018;11:749-61.

39. Bakris GL, Agarwal R, Anker SD, et al. Design and 
Baseline Characteristics of the Finerenone in Reducing Kidney Failure and Disease Progression in Diabetic Kidney Disease Trial. Am J Nephrol 2019;50:333-44.

40. Bakris GL, Agarwal R, Anker SD, et al. Effect of Finerenone on Chronic Kidney Disease Outcomes in Type 2 Diabetes. N Engl J Med 2020;383:2219-29.

41. Heerspink HJL, Parving H-H, Andress DL, et al. Atrasentan and renal events in patients with type 2

Cite this article as: Persson F, Borg R, Rossing P. A narrative review of new treatment options for chronic kidney disease in type 2 diabetes. Ann Transl Med 2021;9(8):716. doi: 10.21037/atm-204841 diabetes and chronic kidney disease (SONAR): a doubleblind, randomised, placebo-controlled trial. Lancet 2019;393:1937-47.

42. de Boer IH, Caramori ML, Chan JCN, et al. Executive summary of the 2020 KDIGO Diabetes Management in CKD Guideline: evidence-based advances in monitoring and treatment. Kidney Int 2020;98:839-48. 